lation and respiration is generally induced by the sulphur waters, and instead of inducing expectoration and subsequent relief to the cough and breathing, the critical improvement has not taken place, and the patients have come away weaker and more oppressed than they went. With all respect for our brethren across the Channel, so far as regards their cleverness in diagnosis, I do not hesitate to say that they are far behind British practitioners in their skill and success in the treatment of disease in general, and of diseases of the chest in particular. The same remark applies pretty much to the German doctors and their water cures, whey cures, and grape cures. Except in a few instances with the waters of Ems, I have hardly known any British pulmonary invalids derive any permanent benefit from these modes of treatment ; but I quite admit that they are sometimes useful when the pulmonary disease is complicated with gout, or decided disorder of the liver and digestive organs.

Of far more importance in the treatment of consumption is change of air and climate. It is of the greatest consequence to the phthisical invalid that he should breathe as pure an air as possible, and that the influence of this pure air on the blood and on the body should be increased by such gentle and varied exercise in it as his strength and the condition of his organs will permit. This is the great object of our sending him to a warm climate in winter, and to a high and dry locality in the summer, that he may be as much as possible in the open air, with its exhilarating and vivifying accessories of light, purity, and freshness, without the chilling operation of cold and wet in the winter, and the enervating and exhausting influence of oppressive heat in the summer. I cannot in this place pursue this important subject into the details of its application to the different forms and stages of disease, and the varieties of air and elimate most suitable for them; but I may refer to my son's little work on climate* for concise information on these points. I would only add further, in conclusion, that several of the most successful cases which have been recorded in these papers are illustrations of the great benefits to be derived from welldirected voyages and change of climate, in addition to the treatment which has been summarised in the present pages.

In conclusion, I trust that the preceding papers have proved what I stated at the commencement: that, powerless as medicine is in the overwhelming and rapid types of pulmonary consumption, it has yet considerable influence over the milder forms; and that under careful treatment life may be prolonged for many years in comfort and usefulness, and in not very few cases the disease is so permanently arrested that it may be called CURED.

\section{OPERATION FOR STRANGULATED HERNIA; ARTIFICIAL ANUS FOR WEEKS, AND ULTIMATE CURE.}

\section{By A. J. MACKIN T OSH, M.D.}

ON the 7th of April last I was requested to visit Mrs. Cof this town, who was suffering from strangulated hernia. Mr. T. G. Wales was then attending her as a private patient, but she was now transferred to me as a pauper. Mr. Wales called upon me in the morning, and acquainted me with the nature of the case and treatment adopted. The ordinary means failed to produce any beneficial effects on the hernia; hence the expediency of having recourse to an operation; besides, the symptoms were growing so urgent that immediate relief was imperative.

In a short time afterwards we operated, having the valuable assistance of Mr. J. K. Hyde. The patient is forty-eight years of age, and the mother of thirteen children; had double hernia for three or four years. She has a delicate constitution, but is neither excitable nor nervous.

The hernia was oblique inguinal on the left side, large and very hard, so much so that no appreciable impression could be made on it by manipulation; this was owing to firm adhesions. She vomited stercoraceous matter shortly before the operation. The pulse was above 120 at the wrist, very weak, and almost imperceptible ; in fact, she was so prostrated and so exhausted that we considered it prudent to operate without the administration of chloroform.

* The Climate of the South of France and its Varieties most suitable for nvalids. By Charles Theodore Williams, MI.B. Oxon. 1867.
When I commenced the operation I found the skin so closely and so firmly adhering to the hernia coverings that I was unable to pinch it up; consequently, I was compelled to divide it by directing the edge of the scalpel inwards. After dividing the integnments, the aspect of things appeared very unfavourable, either for a satisfactory operation or suecessful issue. The investing textures of the hernia were one agglutinated mass of adhesions; also, structural change had advanced to a considerable extent. Some parts were bluish-biack, other parts having either a brownish or greenish hue, and rapidly decom. posing.

To dissect in their order all the different layers which constituted the hernial envelopes was utterly impossible, as they were connected by false membranes into one inseparable and undefinable structure. After dividing a few false and fibrous membranes, we discovered three small perforations in the most prominent part of the hernia ; and from these perforations fæcal matter escaped, and was more or less diffused into the adjacent tissues. This manifestly indicated that a certain portion of the intestine was destroyed. Such being the case, we had no alteruative but to make the three openings into one, thereby constituting an artificial anus. When that was accomplished, a large quautity of the contents of the bowels escaped freely.

During the first twenty-four hours subsequent to the operation, immense quantities of fæcal matter came away through the wound. She progressed remarkably well under the ex. isting circumstances, the new anus answering its purpose well, the motions passing regularly through it without much pain.

On the 13th of April (a week after the operation) I was surprised, on calling in the morning, when she informed me that during the previous night she endured severe pain in the lower part of the abdomen, and that she had a natural motion per rectum just one hour before my visit. She described that motion as " resembling a lot of marbles." I doubted the accuracy of her statements, and questioned the nurse to elicit the truthfulness of her remarks, and, to my no small astonish. ment, found that she corroborated her assertions. At the time, I believed that the peristaltic action of the intestines was restored, and that the contents evacuated were merely lodged in the anal side of the hernia. However, the sequence will show that other important changes occurred besides what I surmised.

On the 23rd of April she had a large motion per rectum, eausing little or no pain. At the same time motions were passing daily through the artificial opening.

On the lst of May she had another free evacuation through the natural passage, and, strange to say, since that date she had daily motions through the natural channel.

When the function of the normal passage was fairly restored the artificial wound gradually closed, and is now completely obliterated, devoid of either discharge or secretion, a little induration and a cicatrix representing the former situation of a hernia and an artificial anus. The patient is now attending to her domestic duties, absolutely free from any pain or suffering. She wears a truss over the hernia on the right side.

I cannot explain the peculiar change that occurred in this very singular and unique case after the operation, except on one hypothesis - that is, that the front half of the strangulated portion of the intestine was destroyed, permitting fæcal matter to escape through it, the other or posterior half being entire and healthy, allowing certain quantities of matter to pass through it also; thereby keeping the calibre of the canal patent, while the greater amount was carried off by the other opening.

It is evident that nature repaired the injured parts most beautifully and successfully by patching the wound with false membranes and adhesions. When this woman dies, a postmortem examination would disclose very curious and interesting facts in her case. It would be highly satisfactory to ascertain the primary state, and amount of mischief to the various parts that were involved by the hernia; also the manner in which nature healed the wound and kept the intestinal eanal open. The exquisite powers of nature are truly wonderful in protecting and saving life in cases that appear to be beyond hope of recovery.

I am not aware that a similar case to this is recorded in the annals of surgery; therefore I am the more anxious to describe it in all its particulars.

Downham Market, Norfolk, July, 1868.

Death of MiddeldorpfF. - This eminent man, who has shed so much lustre on his professorial chair at Breslau, has just died at the early age of forty-four. 